\title{
Older children at the time of the Norwood operation have ongoing mortality vulnerability that continues after cavopulmonary connection
}

\author{
Bahaaldin Alsoufi, MD, ${ }^{\mathrm{a}}$ Cedric Manlhiot, BSc, ${ }^{\mathrm{b}}$ Mamdouh Al-Ahmadi, MD, ${ }^{\mathrm{a}}$ Zohair Al-Halees, MD, ${ }^{\mathrm{a}}$ \\ Brian W. McCrindle, MD, ${ }^{\mathrm{b}}$ Ahmed Yehia Mousa, MD, ${ }^{\mathrm{a}}$ Yasser Al-Heraish, MD, ${ }^{\mathrm{a}}$ and \\ Avedis Kalloghlian, MD
}

\begin{abstract}
Objectives: Delayed first-stage palliation of children with hypoplastic left heart syndrome and related pathologies can be associated with poor outcomes because of development of progressive pulmonary vascular disease and volume load effects on the systemic ventricle and atrioventricular valve. We examine the current era's survival in this subgroup.
\end{abstract}

\begin{abstract}
Methods: Fifty-five infants older than 2 weeks underwent the Norwood operation (2003-2007). Separate competing risk analyses were performed to model outcomes (death and transition to the next stage) after the Norwood operation and after bidirectional cavopulmonary connection.
\end{abstract}

\begin{abstract}
Results: Median age was 32 days (range, 15-118 days). Forty-seven percent had hypoplastic left heart syndrome, and 53\% had other complex univentricular variants. Mean ascending aortic size was $4.4 \pm 1.9 \mathrm{~mm}, 10 \%$ had impaired ventricular function, $11 \%$ had moderate atrioventricular valve regurgitation, and $32 \%$ had restrictive pulmonary venous return. Pulmonary blood flow was established through an aortopulmonary shunt $(\mathrm{n}=30)$ or Sano shunt $(\mathrm{n}=25)$. After the Norwood operation, patients required longer ventilation and more oxygen and nitric oxide and had higher inotropic scores compared with those undergoing the traditional management protocol. Competing risks analysis showed that 2 years after the Norwood operation, $39 \%$ had died, and $57 \%$ underwent bidirectional cavopulmonary connection. Four years after bidirectional cavopulmonary connection, $15 \%$ had died, and $85 \%$ underwent the Fontan operation. Overall 3-year survival after the Norwood operation was $53 \%$. Factors associated with mortality were age, lower weight at the time of the Norwood operation, impaired ventricular function, longer circulatory arrest, and lower pre-bidirectional cavopulmonary connection saturation.

Conclusions: Children older than 2 weeks undergoing the Norwood operation frequently require postoperative pulmonary vasodilatation and high inotropic support. A significant hazard of death persists through all steps of multistage palliation. Increased pulmonary vascular resistance and volume load effects, such as systemic ventricular impairment and atrioventricular valve regurgitation, are commonly evident in patients in whom treatment fails or who do not qualify to proceed to the next stage of palliation. Those patients should be closely monitored for timely referral for heart transplantation when indicated. (J Thorac Cardiovasc Surg 2011;142:142-7)
\end{abstract}

Supplemental material is available online.

Multistage palliation is currently the standard treatment for hypoplastic left heart syndrome (HLHS) and other related

\footnotetext{
From the King Faisal Heart Institute, ${ }^{\mathrm{a}}$ King Faisal Specialist Hospital and Research Center, Riyadh, Saudi Arabia; and the Labatt Family Heart Center, ${ }^{\mathrm{b}}$ the Hospital for Sick Children and the University of Toronto, Toronto, Ontario, Canada.

Disclosures: Authors have nothing to disclose with regard to commercial support.

Read at the 36th Annual Meeting of The Western Thoracic Surgical Association, Ojai, California, June 23-26, 2010.

Received for publication July 28, 2010; revisions received Dec 28, 2010; accepted for publication Jan 19, 2011; available ahead of print April 8, 2011.

Address for reprints: Bahaaldin Alsoufi, MD, King Faisal Heart Institute (MBC 16), King Faisal Specialist Hospital and Research Center, PO Box 3354, Riyadh, Saudi Arabia 11211 (E-mail: balsoufi@hotmail.com).

0022-5223/\$36.00

Copyright (C) 2011 by The American Association for Thoracic Surgery doi: $10.1016 /$ j.jtcvs.2011.01.064
}

complex, single-ventricle malformations in the majority of cardiac centers. ${ }^{1-6}$ Results of first-stage palliation have significantly improved in the last decade because of refinements in preoperative care, surgical and perfusion techniques, postoperative care, and monitoring. ${ }^{7-15}$

Several previous reports have demonstrated that first-stage palliation performed in infants older than 2 to 4 weeks of age is associated with a significant increase in mortality. ${ }^{2-4,6,16}$ This was ascribed to the development of pulmonary vascular disease, which complicated the postoperative course and predisposed the infants to potentially fatal pulmonary hypertensive crises in addition to the effects of prolonged volume load on the single ventricle with subsequent dysfunction and on the atrioventricular valve (AVV) with subsequent regurgitation, with a significant negative effect on early and late outcomes. ${ }^{17,18}$

Despite multiple existing current large series demonstrating improved results of first-stage palliation, the number of 


$$
\begin{aligned}
& \text { Abbreviations and Acronyms } \\
& \begin{aligned}
\mathrm{AVV} & =\text { atrioventricular valve } \\
\mathrm{BCPC} & =\text { bidirectional cavopulmonary } \\
& \text { connection } \\
\mathrm{ECMO} & =\text { extracorporeal membrane oxygenation } \\
\mathrm{FIO}_{2} & =\text { fraction of inspired oxygen } \\
\mathrm{HLHS} & =\text { hypoplastic left heart syndrome } \\
\mathrm{mBTS} & =\text { modified Blalock-Taussig shunt } \\
\mathrm{PE} & =\text { parameter estimate } \\
\mathrm{PVR} & =\text { pulmonary vascular resistance } \\
\mathrm{RV}-\mathrm{PA} & =\text { right ventricle-pulmonary artery } \\
\mathrm{SE} & =\text { standard error }
\end{aligned}
\end{aligned}
$$

at http://www.clevelandclinic.org/heartcenter/hazard). The HAZARD procedure uses maximum likelihood estimates to resolve risk distribution of time to event in up to 3 phases of risk (early, constant, and late). Competing risk analysis was performed to model the probability over time of each of 2 mutually exclusive end points after first-stage palliation and after BCPC: death and survival to the next stage of palliation and the remaining patients beginning alive and not qualifying for the next stage of palliation. Variables potentially influencing the likelihood of outcomes in the competing risk models were sought from demographic, anatomic, and surgical variables through a stepwise regression algorithm $(P<.05$ to enter) for each phase of risk. Effects of covariates on the probability of outcomes in competing risk models are given as parameter estimates (PEs) and standard errors (SEs). The clinical relevance of covariates of interest on likelihood of selected outcomes was established by solving the regression equations for multiple "typical" test patients. All statistical analyses were performed with SAS statistical software version 9.1 (SAS Institute, Inc, Cary, NC).

\section{RESULTS \\ Patient Cohort}

During the study period, 55 infants older than 14 days underwent Norwood-type first-stage palliation. There were 37 $(65 \%)$ male and $18(35 \%)$ female patients. The age range was 15 to 118 days and included 12 patients 2 to 3 weeks old, 12 patients 3 to 4 weeks old, and 31 patients more than 4 weeks old. Complete patients' characteristics are detailed in Table 1.

\section{MATERIALS AND METHODS Inclusion Criteria}

From 2003 to 2007, 55 consecutive infants with variable singleventricle pathologies underwent Norwood-type first-stage palliation at an age of greater than 14 days at the King Faisal Specialist Hospital and Research Center in Riyadh, Saudi Arabia. Clinical, operative, and outcome data were abstracted from patients' medical records. Approval of this study was obtained from the research ethics board at our institution, and requirement for individual consent was waived for this observational study.

\section{Operative Details}

The surgical procedure consisted of standard first-stage Norwood palliation with division of the main pulmonary artery and side-to-side anastomosis with the ascending aorta, aortic arch augmentation and reconstruction, and atrial septectomy. Pulmonary blood flow was established with either a modified Blalock-Taussig shunt (mBTS) or a right ventricle-pulmonary artery (RV-PA) conduit based on the individual surgeon's preference. During arch reconstruction, deep hypothermic circulatory arrest and selective antegrade cerebral perfusion, isolated or in combination, were used at the surgeon's discretion.

\section{Follow-up}

Time-related outcomes were determined from recent office visits at King Faisal Specialist Hospital and Research Center and from direct correspondence with patients' families. Follow-up was complete. Mean followup was $2.2 \pm 2.1$ years for the entire cohort and $2.8 \pm 2.0$ years for patients who survived to hospital discharge after the first stage.

\section{Statistical Analysis}

Data are presented as means with standard deviations, medians with minimums and maximums, and frequencies, as appropriate. Timedependent mutually exclusive outcomes (death and survival to the next stage of palliation) after first-stage palliation and after bidirectional cavopulmonary connection (BCPC) were parametrically modeled. Parametric probability estimates for time-dependent outcomes use models based on multiple overlapping phases of risk (available for use with the SAS system

\section{First-Stage Palliation}

At the time of first-stage palliation, pulmonary blood flow was restored by means of mBTS in $29(54 \%)$ patients and by means of an RV-PA conduit in $24(44 \%)$ patients, with $1(2 \%)$ patient requiring both. One patient in whom the shunt type is not well documented died in the operating room. Mean mBTS diameter was $3.9 \pm 0.3 \mathrm{~mm}$, and mean RV-PA conduit size was $5.7 \pm 0.5 \mathrm{~mm}$. Mean cardiopulmonary bypass time was $139 \pm 43$ minutes, mean aortic crossclamp time was $68 \pm 20$ minutes, and mean deep hypothermic circulatory arrest time was $42 \pm 22$ minutes.

Five patients required postoperative extracorporeal membrane oxygenation (ECMO), and none of them survived. Three patients required shunt revision, and 2 of them died. Other reoperations included diaphragmatic plication in 5 patients and evacuation of a seroma compressing on the shunt and pulmonary arteries in 1 patient.

Inotrope use was quantified by a revised score adapted from Wernovsky and colleagues. ${ }^{19}$ The score was calculated by obtaining the average amount of inotropic support the patients received at the first 3 postoperative days (excluding patients receiving ECMO support) and then entering the data into the following equation:

Inotrope score: Dopamine + Dobutamine $+([$ Epinephrine + Norepinephrine $] \times 100)+($ Milrinone $\times 20)$.

Units of inotrope dosage used in this equation were in micrograms per kilogram per minute. The average inotropic 
TABLE 1. Complete characteristics for the entire patient cohort $(\mathbf{n}=\mathbf{5 5})$

\begin{tabular}{lc}
\hline Age at first-stage palliation (d), median (range) & $32(15-118)$ \\
Male sex, $\mathrm{n}(\%)$ & $37(65)$ \\
Mean weight (kg) & $3.1 \pm 0.6$ \\
Diagnosis & \\
HLHS, n (\%) & $26(47 \%)$ \\
Non-HLHS, n (\%) & $29(53 \%)$ \\
$\quad$ Double-inlet left ventricle & 11 \\
$\quad$ Double-outlet right ventricle & 6 \\
$\quad$ Severe Shone complex & 3 \\
$\quad$ Unbalanced atrioventricular septal defect & 2 \\
$\quad$ Tricuspid atresia & 2 \\
$\quad$ Other & 5 \\
Dominant ventricular morphology, n (\%) & \\
Left & $17(31 \%)$ \\
Right & $38(69 \%)$ \\
Dominant ventricular function & \\
$\quad$ Normal & $90 \%$ \\
Mildly impaired & $4 \%$ \\
$\quad$ Moderately impaired & $6 \%$ \\
Dominant atrioventricular valve function & \\
Competent or trivial regurgitation & $63 \%$ \\
Mild regurgitation & $26 \%$ \\
Moderate regurgitation & $11 \%$ \\
Aortic atresia & $28 \%$ \\
Mitral atresia & $31 \%$ \\
Restrictive pulmonary venous return & $32 \%$ \\
Ascending aortic diameter (mm) & $4.4 \pm 1.9$ \\
Situs inversus/dextrocardia & 1 \\
Genterrupted aortic arch & 2 \\
Extracardiac malformations & 0 \\
\hline$H L H S$ Hypoplastic left heart syndrome & 0 \\
\hline
\end{tabular}

HLHS, Hypoplastic left heart syndrome.

score in the first 3 days was $38 \pm 26$ per day and was lower for first-stage survivors ( $32 \pm 14$ per day) versus nonsurvivors $(58 \pm 44$ per day, $P<.0001)$. The average oxygen saturation in the first 3 days was $70 \% \pm 6 \%$, and the average fraction of inspired oxygen $\left(\mathrm{FIO}_{2}\right)$ was $50 \% \pm 16 \%$. Nitric oxide use was required in 12 patients. Median ventilation duration in first-stage survivors was 18 days (range, 2-108 days).

The difference in postoperative parameters between firststage hospital survivors versus nonsurvivors is shown in Table 2.

\section{Competing Risk Analysis After First-Stage Palliation}

After the 55 initial Norwood-type first-stage palliative procedures, $31(56 \%)$ patients underwent BCPC, and $22(40 \%)$ patients died before BCPC. In addition, $1(2 \%)$ patient in whom the superior vena cava was obstructed proceeded immediately to the Fontan operation and, $1(2 \%)$ remaining patient remains alive but did not qualify for BCPC because of severe neurologic insult after a central nervous system infection that was unrelated to the cardiac procedure.

The competing risks analysis after first-stage palliation showed that at 1 year after first-stage palliation, approximately $37 \%$ of patients had died, and $54 \%$ had undergone BCPC. By 2 years after first-stage palliation, 39\% have died, and 58\% have proceeded to the next stage of palliation (Figure 1).

Factors associated with higher mortality after first-stage palliation were sought, and results are shown in Table 3. Significant factors for mortality included lower weight (PE, +0.84 [SE, 0.41]; $P=.04$ ), longer deep hypothermic circulatory arrest (PE, +0.20 [SE, 0.09]/10 min; $P=.03$ ), impaired dominant ventricular function $(\mathrm{PE},+1.20$ [SE, $0.57] ; P=.04$ ), and age category less than 3 weeks (PE, +1.05 [SE, 0.46], $P=.03$ ).

\section{Competing Risks Analysis After Second-Stage Palliation}

Thirty-one patients underwent BCPC. Hemodynamic and echocardiographic parameters before $\mathrm{BCPC}$ are listed in Table E1. BCPC was right sided $(\mathrm{n}=28)$, left sided $(\mathrm{n}=1)$, and bilateral $(\mathrm{n}=2)$. Eight patients had preparation for a subsequent interventional Fontan operation at the time of BCPC. Additional cardiac procedures were performed in 15 patients and included pulmonary artery augmentation $(\mathrm{n}=12)$, arch augmentation $(\mathrm{n}=1)$, AVV repair $(\mathrm{n}=2)$, AVV closure $(\mathrm{n}=1)$, and permanent pacemaker insertion $(\mathrm{n}=1)$. One patient required postoperative takedown of the BCPC and placement of an MBTS because of increased pulmonary vascular resistance (PVR).

After the 31 BCPC procedures, $26(84 \%)$ patients underwent the Fontan procedure, and $5(16 \%)$ patients died before the Fontan procedure. The competing risks analysis after second-stage palliation showed that at 2 years after second-stage palliation, approximately $15 \%$ of patients had died, and $43 \%$ had undergone the Fontan procedure, with the remaining $43 \%$ alive and awaiting the Fontan

TABLE 2. Postoperative care parameters after first-stage palliation in infants older than 2 weeks at the time of the operation

\begin{tabular}{|c|c|c|c|c|}
\hline & Overall & Survivors & Nonsurvivors & $P$ value \\
\hline Average 3 -d inotropic score* & $38 \pm 26 / d$ & $32 \pm 14 / d$ & $58 \pm 44 / d$ & $<.0001$ \\
\hline Average 3-d oxygen saturation & $70 \% \pm 6 \%$ & $71 \% \pm 6 \%$ & $68 \% \pm 9 \%$ & .02 \\
\hline Average $3-\mathrm{d} \mathrm{FIO}_{2}$ use & $50 \% \pm 16 \%$ & $48 \% \pm 14 \%$ & $58 \% \pm 20 \%$ & .10 \\
\hline Average 3 -d oxygen saturation/ $/ \mathrm{FIO}_{2}$ ratio & $1.6 \pm 0.6$ & $1.6 \pm 0.6$ & $1.4 \pm 0.7$ & .50 \\
\hline Nitric oxide use & 12 patients & 7 patients & 5 patients & \\
\hline
\end{tabular}

All units are in micrograms per kilogram per minute. $\mathrm{FIO}_{2}$, Fraction of inspired oxygen. ${ }^{*}$ Inotrope score: Dopamine + Dobutamine $+([$ Epinephrine + Norepinephrine $] \times 100)+$ (Milrinone $\times 20$ ). 


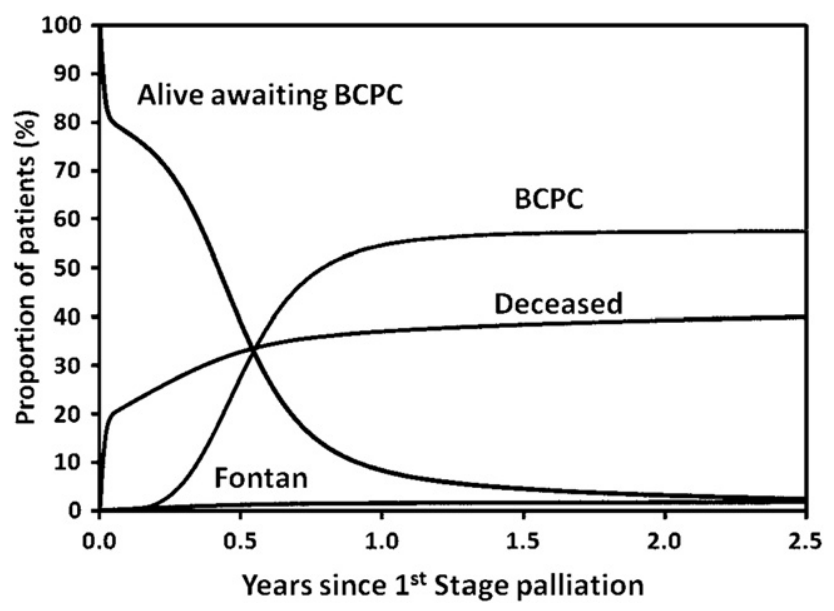

FIGURE 1. Competing risks depiction of events (death and transition to bidirectional cavopulmonary connection, with the remaining few patients alive and awaiting bidirectional cavopulmonary connection or transitioning directly to the Fontan operation) after Norwood-type first-stage palliation of HLHS and related pathologies in infants greater than 2 weeks of age.

procedure. By 4 years after second-stage palliation, 15\% have died, and the remaining $85 \%$ have proceeded to the Fontan procedure (Figure 2).

Factors associated with higher mortality after BCPC were sought, and results are shown in Table 3. Significant factors for mortality included smaller ascending aortic size (PE, $+0.82[\mathrm{SE}, 0.42] / \mathrm{mm} ; P=.05$ ), higher pre-Glenn procedure transpulmonary gradient $(\mathrm{PE},+0.20$ [SE, 0.11]/ $\mathrm{mm} \mathrm{Hg} ; P=.06$ ), and age category less than 3 weeks at

TABLE 3. Risk factors for death in patients older than 2 weeks at firststage palliation

\begin{tabular}{lcc}
\hline & $\begin{array}{c}\text { Parameter } \\
\text { estimate } \\
\text { (standard error) }\end{array}$ & $\begin{array}{c}P \\
\text { value }\end{array}$ \\
\hline 1. Factors associated with death after the Norwood operation (before BCPC) \\
Longer DHCA time (per 10 min) & $0.20(0.09)$ & .03 \\
Lower weight at time of operation (per kg) & $0.84(0.41)$ & .04 \\
Impaired dominant ventricular function & $1.20(0.57)$ & .04 \\
Age group $<3$ wk & $1.05(0.46)$ & .03 \\
2. Factors associated with death after BCPC (before the Fontan procedure) \\
Higher transpulmonary gradient & $0.20(0.10)$ & .06 \\
Smaller ascending aortic size & $0.82(0.42)$ & .05 \\
Age group $<3$ wk at time of Norwood & $1.94(0.92)$ & .04 \\
$\quad$ operation & & \\
3. Factors associated with overall mortality & $0.48(0.24)$ & .05 \\
Age group $<3$ wk at time of Norwood & & \\
$\quad$ operation & $0.99(0.53)$ & .06 \\
Impaired dominant ventricular function & $0.57(0.32)$ & .07 \\
Lower weight category (<2.5 vs $>2.5 \mathrm{~kg})$ & $0.03(0.01)$ & .01 \\
Longer DHCA time (min) & $0.06(0.04)$ & .09 \\
Lower oxygen saturation before BCPC & \\
$\quad$ (per \%) & \\
\hline DHCA, Deep hypothermic circulatory arrest; $B C P C$, bidirectional cavopulmonary \\
connection.
\end{tabular}

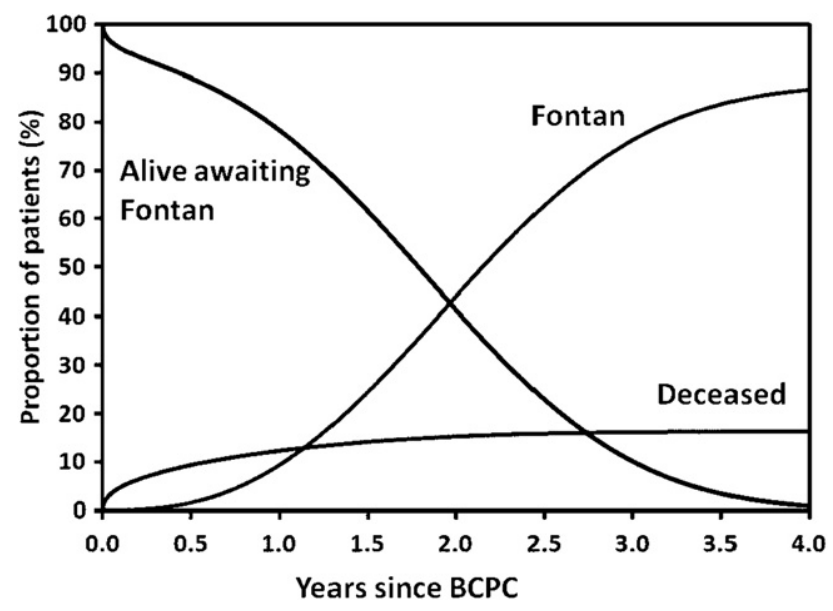

FIGURE 2. Competing risks depiction of events (death and transition to the Fontan operation) after bidirectional cavopulmonary connection $(B C P C)$ in infants who underwent Norwood-type first-stage palliation at greater than 2 weeks of age.

the time of the Norwood operation (PE, +1.94 [SE, 0.92]; $P=.04)$.

Of note, 3 patients died after the Fontan procedure, 2 in the perioperative period and 1 after reoperation for pulmonary venous obstruction. Hemodynamic and echocardiographic parameters before the Fontan procedure are listed in Table E1.

\section{Overall Survival}

Overall 3-year survival after first-stage palliation was $53 \%$. The hazard function for death was characterized by a pronounced early hazard phase in the immediate postoperative period but a persistent constant hazard phase that continued up to 1.5 years after first-stage palliation (Figure 3).

Factors associated with overall mortality are shown in Table 3. The relationship between overall survival and patient weight at the time of the operation is shown in Figure E1. Of note, there were trends for decreased survival in patients with dominant right ventricular morphology (Figure E2) and with the use of an RV-PA conduit (Figure E3), although those trends did not reach statistical significance. The events after first-stage palliation in the entire cohort of patients is shown in Figure E4.

\section{DISCUSSION}

Despite multiple reports from different institutions demonstrating significant improvement in hospital survival after first-stage palliation of HLHS and other complex singleventricle pathologies, little information is available regarding contemporary outcomes in infants older than 2 weeks at the time of the operation. ${ }^{7-15}$ Older age was identified as a significant risk factor for hospital and interstage mortality 

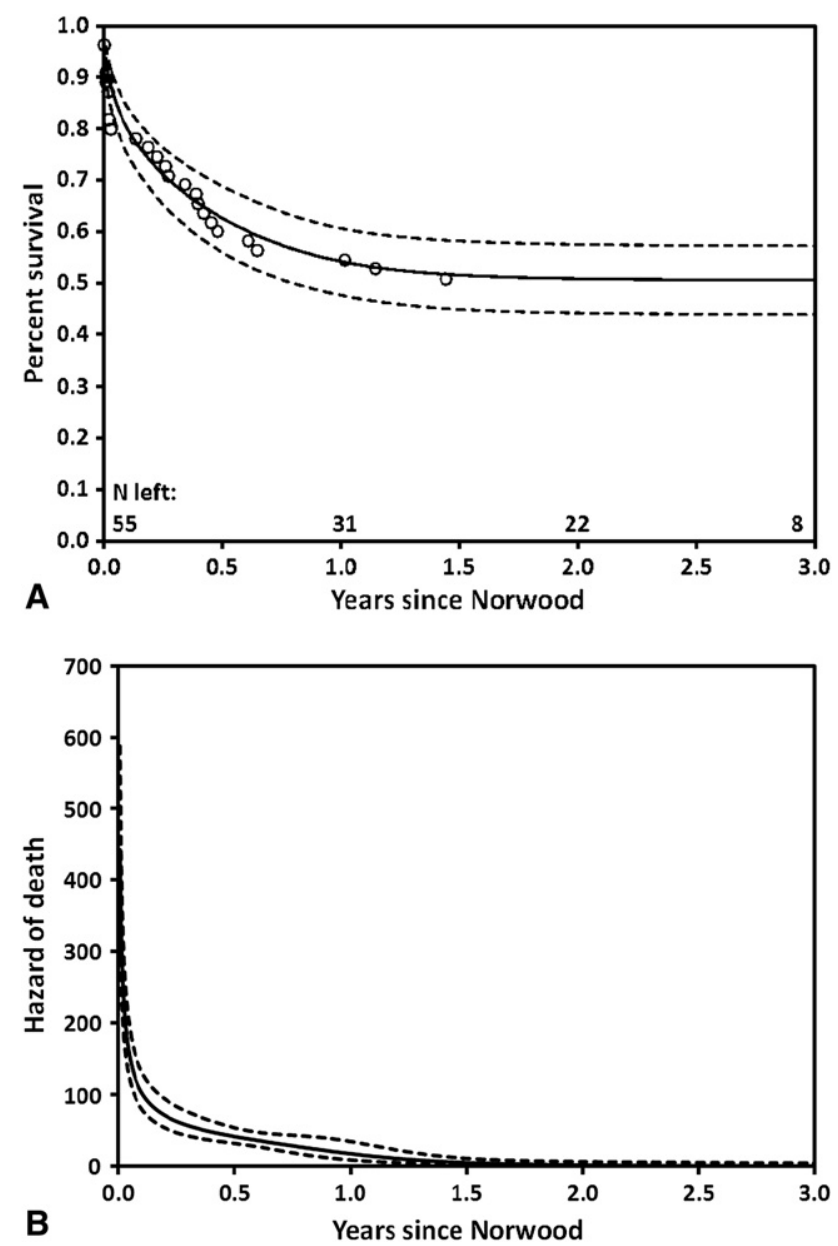

FIGURE 3. Time-dependent survival (A) and hazard risk of death (B) over time after Norwood-type first-stage palliation. The hazard function for death is characterized by the presence of an early hazard phase during the initial few months after surgical intervention. After that period, there is a constant attrition that continues up to 2 years after the initial operation. The solid lines in the parametric model represent parametric point estimates, and the dashed lines enclose the $95 \%$ confidence interval. Circles represent nonparametric estimates.

in many prior reports..$^{2-4,6,16}$ Nonetheless, most available current large series contain few patients older than 2 weeks at the time of the Norwood operation, and therefore it is not clear whether this subgroup of patients benefited from this recent trend of superior results. ${ }^{7-15}$

At our institution, we continue to assess many patients with various complex single-ventricle anomalies at older ages because of the tertiary nature of our practice as the sole provider for Norwood-type palliation in the region. Our unique experience prompted us to review contemporary outcomes in a relatively large consecutive cohort of older infants at the time of first-stage palliation. Surgical delays in our current series were not related in general to poor preoperative status, sepsis, or multiorgan failure but rather to late presentation or referral.
One of our principal findings was the distinctive postoperative course in this subgroup of patients. The mainstay of postoperative treatment after the Norwood operation is achieving a balance between the pulmonary and systemic circulations. Systemic afterload reduction and ventilator management to avoid pulmonary overcirculation are commonly used in the postoperative care of neonates after the Norwood operation. ${ }^{7,14,15}$ In our older patients, however, a different treatment philosophy is often required. Many of our patients exhibit signs of poor pulmonary circulation and require high oxygen concentrations and pulmonary vasodilators, such as nitric oxide, to promote blood flow to the lungs. In addition, there is often very little room for systemic vasodilatation, and those infants often require inotropic support and vasopressors, as demonstrated by the high inotropic score in the initial 3 postoperative days. This distinct postoperative requirement can be explained by the effects of delayed surgical intervention, such as the development of progressive pulmonary vascular disease, chronic volume load causing development of postoperative ventricular dysfunction, or AVV regurgitation. Moreover, older infants in our series required high oxygen concentration, had low oxygen saturation, and required prolonged ventilation and subsequent prolonged intensive care unit and hospital stays. ECMO support was largely ineffective in our patient population, especially because the heart transplantation option was not offered to this age group at our institution.

Additionally, we noted a high interstage mortality in our patient cohort, with only $60 \%$ of all patients proceeding to the next stage of palliation. This high interstage mortality in older infants has been noted by other investigators. Hehir and colleagues ${ }^{16}$ showed that the Norwood operation at greater than 7 days of age is a significant risk factor for interstage mortality. In addition to residual lesions and shuntrelated problems, ${ }^{13,20}$ high PVR and a reactive pulmonary vascular bed expose those infants to the risk of pulmonary hypertension crises that can be often fatal and might be implicated in this high occurrence of interstage mortality. We have noted many incidents of pulmonary hypertension in our patient cohort while in the hospital with subsequent respiratory and hemodynamic compromise, cardiac arrest, and occasional mortality. This tendency likely continues after discharge to contribute to this disturbingly high rate of sudden death at home.

Although the risk of mortality is usually greatly eliminated when a balanced circulation is achieved by means of BCPC with eradication of shunt problems, coronary steal risk, volume load effects, and management of any residual lesions. ${ }^{3,6,13}$ In our series we observed that those older patients do not enjoy this stabilization of mortality risk with time, and the hazard of death continues after BCPC almost up to 2 years after the Norwood procedure. Pulmonary vascular disease, ventricular dysfunction, and 
AVV regurgitation were evident in most patients who did not progress to the next stage of palliation or died after subsequent palliative procedures in our series. This finding highlights the importance of continued close follow-up of those patients for timely referral for heart transplantation when indicated.

Several demographic, anatomic, operative, and hemodynamic variables were analyzed to determine factors that significantly affect survival. Some trends that did not reach statistical significance merit some discussion. We have noted that patients who received mBTSs as a source of pulmonary blood flow at the time of first-stage palliation had a trend for improved survival compared with those who received RV-PA conduits. Although RV-PA conduits have been shown to facilitate postoperative care and even to decrease early mortality in some series, ${ }^{8,11,12}$ this was not the case in older patients in our series. The benefit of the RVPA conduit is diluted in this subgroup of patients in whom pulmonary overcirculation and subsequent coronary steal are not major problems. In addition, lower saturations achieved by the RV-PA conduit, especially in the setting of increased PVR, and the effects of ventriculotomy, especially in those patients with ventricular dysfunction caused by chronic volume load, might all contribute to the surprisingly worse survival seen in older patients who received RV-PA conduit.

We have also noted that patients with dominant left ventricular morphology had a trend toward improved survival. This finding might be explained by the fact that morphologic left ventricles are more equipped to tolerate higher afterload and volume load and therefore might be more resilient to the sequelae of delayed first-stage palliation.

Of interest, the outcomes in the oldest patients in our series, those older than 4 weeks, were not worse than those 2 to 4 weeks old. This might be explained by a more selective approach to the older patients at our institution but definitely highlights that the development of pulmonary vascular disease is unpredictable and that the relationship between PVR and age in days is not linear, at least within the age margins of our patient cohort.

In conclusion, infants older than 2 weeks at the time of Norwood-type first-stage palliation comprise a unique subgroup of patients. Postoperative care is different from traditional management, with a higher likelihood of requirement of inotropes, vasopressors, and pulmonary vasodilators. Despite improved outlook of patients undergoing Norwoodtype operations in the recent era, older infants at the time of first-stage palliation continue to be exposed to the hazard of death that continues beyond the perioperative and interstage periods and throughout all steps of multistage palliation. This vulnerability is mostly the product of delayed operation because of the development of pulmonary vascular disease and ventricular dysfunction. Careful preoperative assessment of those infants is necessary for selection of the most appropriate procedure, and vigilant follow-up is necessary for timely referral for heart transplantation, as indicated in patients not proceeding to the next stage of palliation.

\section{References}

1. Alsoufi B, Bennetts J, Verma S, Caldarone CA. New developments in the treat ment of hypoplastic left heart syndrome. Pediatrics. 2007;119:109-17.

2. Mahle WT, Spray TL, Wernovsky G, Gaynor JW, Clark BJ. Survival after reconstructive surgery for hypoplastic left heart syndrome. Circulation. 2000; 102(suppl 3):III136-41.

3. Bove EL, Lloyd TR. Staged reconstruction for hypoplastic left heart syndrome Contemporary results. Ann Surg. 1996;224:387-94.

4. Iannettoni MD, Bove EL, Mosca RS, Lupinetti FM, Dorostkar PC, Ludomirsky A, et al. Improving results with first-stage palliation for hypoplastic left heart syndrome. J Thorac Cardiovasc Surg. 1994;107:934-40.

5. Azakie T, Merklinger SL, McCrindle BW, Van Arsdell GS, Lee KJ, Benson LN, et al. Evolving strategies and improving outcomes of the modified Norwood procedure: a 10-year single-institution experience. Ann Thorac Surg. 2001;72: 1349-53.

6. Ashburn DA, Blackstone EH, Wells WJ, Jonas RA, Pigula FA, Manning PB et al. Determinants of mortality and type of repair in neonates with pulmonary atresia and intact ventricular septum. J Thorac Cardiovasc Surg. 2004; 127:1000-7.

7. Tweddell JS, Hoffman GM, Mussatto KA, Fedderly RT, Berger S, Jaquiss RD et al. Improved survival of patients undergoing palliation of hypoplastic left heart syndrome: lessons learned from 115 consecutive patients. Circulation. 2002; 106(suppl 1):I82-9.

8. McGuirk SP, Griselli M, Stumper O, Rumball EM, Miller P, Dhillon R, et al Staged surgical management of hypoplastic left heart syndrome: a singleinstitution 12-year experience. Heart. 2006;92:364-70.

9. Gaynor JW, Mahle WT, Cohen MI, Ittenbach RF, DeCampli WM, Steven JM, et al. Risk factors for mortality after the Norwood procedure. Eur J Cardiothorac Surg. 2002;22:82-9.

10. Stasik CN, Gelehrter S, Goldberg CS, Bove EL, Devaney EJ, Ohye RG. Current outcomes and risk factors for the Norwood procedure. J Thorac Cardiovasc Surg. 2006;131:412-7

11. Sano S, Ishino K, Kawada M, Honjo O. Right ventricle-pulmonary artery shunt in first-stage palliation of hypoplastic left heart syndrome. Semin Thorac Cardiovasc Surg Pediatr Card Surg Annu. 2004;7:22-31.

12. Pizarro C, Mroczek T, Malec E, Norwood WI. Right ventricle to pulmonary artery conduit reduces interim mortality after stage 1 Norwood for hypoplastic left heart syndrome. Ann Thorac Surg. 2004;78:1959-63.

13. Ghanayem NS, Hoffman GM, Mussatto KA, Cava JR, Frommelt PC, Rudd NA, et al. Home surveillance program prevents interstage mortality after the Norwood procedure. J Thorac Cardiovasc Surg. 2003;126:1367-77.

14. Bradley SM, Atz AM. Postoperative management: the role of mixed venous oxygen saturation monitoring. Semin Thorac Cardiovasc Surg Pediatr Card Surg Апnи. 2005;22-7.

15. De Oliveira NC, Van Arsdell GS. Practical use of alpha blockade strategy in the management of hypoplastic left heart syndrome following stage one palliation with a Blalock-Taussig shunt. Semin Thorac Cardiovasc Surg Pediatr Card Surg Annu. 2004;7:11-5.

16. Hehir DA, Dominguez TE, Ballweg JA, Ravishankar C, Marino BS, Bird GL, et al. Risk factors for interstage death after stage 1 reconstruction of hypoplastic left heart syndrome and variants. J Thorac Cardiovasc Surg. 2008;136:94-9, e1-3.

17. Rossi AF, Sommer RJ, Steinberg LG, Gross RP, Seiden HS, Golinko RJ, et al Effect of older age on outcome for stage one palliation of hypoplastic left heart syndrome. Am J Cardiol. 1996;77:319-21.

18. Duncan BW, Rosenthal GL, Jones TK, Lupinetti FM. First-stage palliation of complex univentricular cardiac anomalies in older infants. Ann Thorac Surg. 2001;72:2077-80.

19. Wernovsky G, Wypij D, Jonas RA, Mayer JE Jr, Hanley FL, Hickey PR, et al. Postoperative course and hemodynamic profile after the arterial switch operation in neonates and infants. A comparison of low-flow cardiopulmonary bypass and circulatory arrest. Circulation. 1995;92:2226-35.

20. Bartram U, Grunenfelder J, Van Praagh R. Causes of death after the modified Norwood procedure: a study of 122 postmortem cases. Ann Thorac Surg. 1997;64:1795-802 


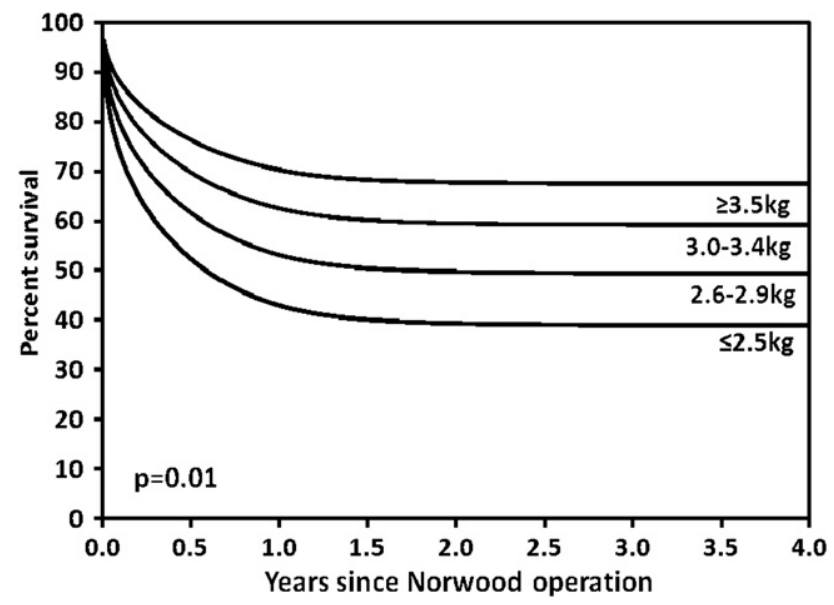

FIGURE E1. Parametric model for survival after first-stage palliation stratified by weight group at the time of the initial operation. Lower weight was associated with higher mortality.

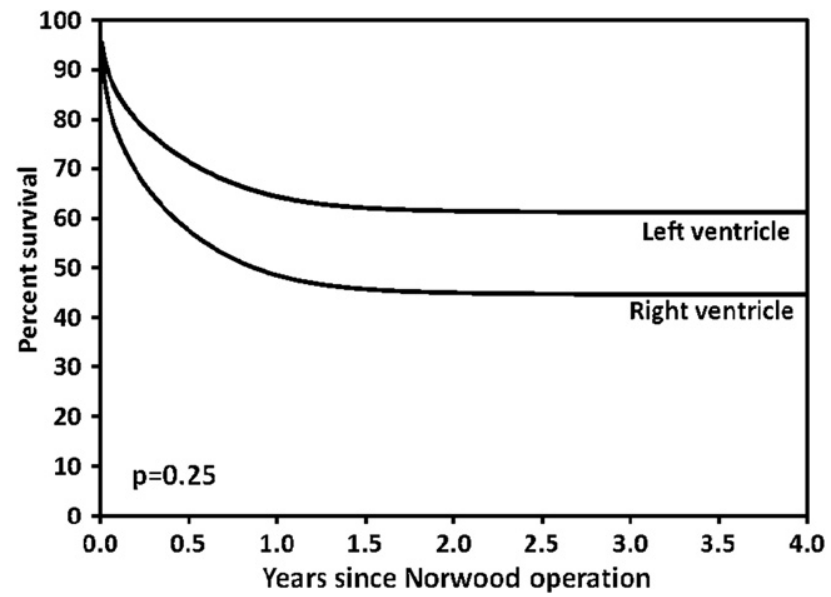

FIGURE E2. Parametric model for survival after first-stage palliation stratified by dominant ventricular morphology. There was a trend for improved survival in patient with dominant left ventricular morphology compared with that seen in patients with dominant right ventricular morphology.

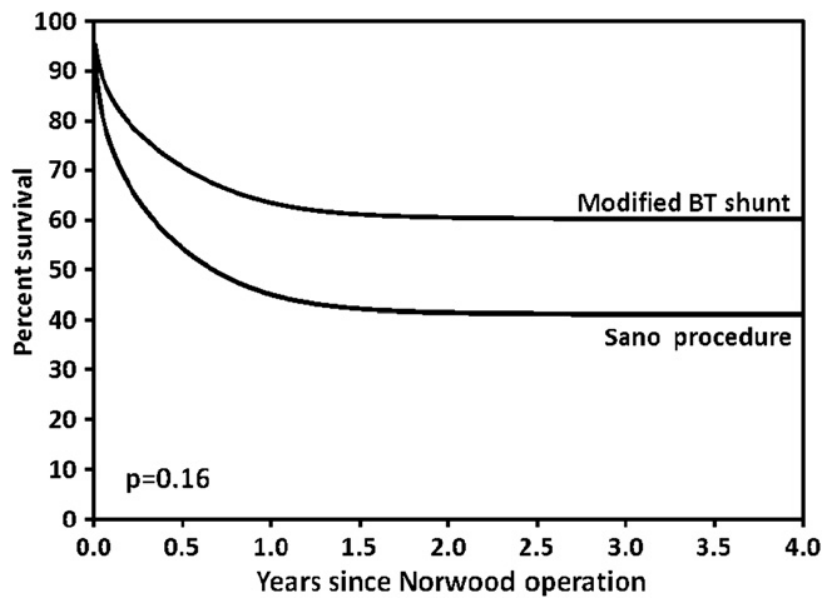

FIGURE E3. Parametric model for survival after first-stage palliation stratified by the type of shunt at the time of first-stage palliation. There was a trend for improved survival in patients who had a modified Blalock-Taussig shunt compared with that seen in patients who had a right ventricle-pulmonary artery conduit (Sano shunt).

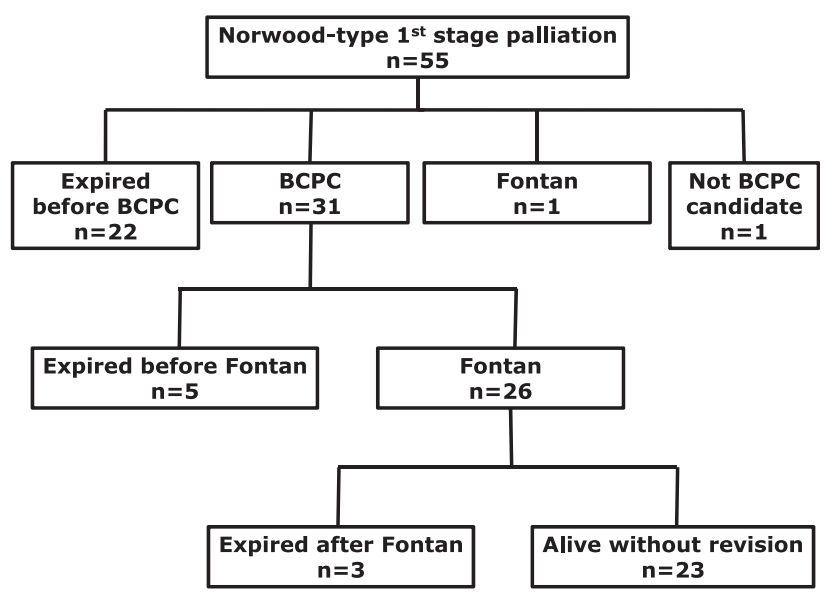

FIGURE E4. Flow chart depicting events after first-stage Norwood-type palliation in 55 infants older than 2 weeks of age at the time of the operation. $B C P C$, Bidirectional cavopulmonary connection. 
TABLE E1. Echocardiographic and hemodynamic parameters before BCPC and before the Fontan procedure

\begin{tabular}{lcc}
\hline & Pre-BCPC $(\mathbf{n}=\mathbf{3 3})$ & Pre-Fontan $(\mathbf{n}=\mathbf{2 7})$ \\
\hline Mean PA pressure (mm Hg) & $17 \pm 5$ & $14 \pm 3$ \\
Mean ventricular EDP (mm Hg) & $10 \pm 3$ & $10 \pm 3$ \\
Mean transpulmonary gradient (mm Hg) & $7 \pm 5$ & $4 \pm 3$ \\
PVR index (Woods units) & $2.3 \pm 1.2$ & $1.7 \pm 0.8$ \\
Oxygen saturation (\%) & $70 \pm 8$ & $83 \pm 5$ \\
AVV regurgitation & Mild $=17(52 \%)$ & Mild $=3(11 \%)$ \\
& Moderate $=3(9 \%)$ & Moderate $=2(7 \%)$ \\
Dominant ventricular function & Mildly impaired $=3(9 \%)$ & Mildly impaired $=2(7 \%)$ \\
& Moderately impaired $=3(9 \%)$ & Moderately impaired $=0(0 \%)$ \\
$B C P C$, Bidirectional cavopulmonary connection; $E D P$, end-diastolic pressure; $P V R$, pulmonary vascular resistance; $A V V$, atrioventricular valve.
\end{tabular}

